NREL/CP-540-46533. Posted with permission.

Presented at the 2009 SAE Powertrain, Fuels, and Lubricants Meeting

November 2-4, 2009, San Antonio, Texas

2009-01-2733

\title{
On-Road and In-Laboratory Testing to Demonstrate Effects of ULSD, B20, and B99 on a Retrofit Urea-SCR Aftertreatment System
}

\author{
Kevin Walkowicz \\ National Renewable Energy Laboratory \\ Kwangsam Na, William Robertson, Keshav Sahay \\ California Air Resources Board \\ Mike Bogdanoff \\ South Coast Air Quality Management District \\ Chris Weaver \\ Engine, Fuel, and Emissions Engineering, Inc. \\ Richard Carlson \\ Extengine Systems, Inc.
}

\begin{abstract}
In order to demonstrate the performance of a retrofitted selective catalytic reduction (SCR) system while also addressing the issues associated with greater use of biodiesel, a 2005 International 9200i tractor owned by the City of Santa Monica was retrofitted with a titaniavanadia-tungsten catalyst and a urea dosing system supplied by Extengine Systems, Inc. This tractor was operated under normal service conditions within the City of Santa Monica refuse collection and transportation fleet. An on-board emissions measurement system supplied by Engine, Fuel, and Emissions Engineering, Inc., was installed on the vehicle; it measured the emissions and fuel use of the vehicle while it operated on ultra-low-sulfur diesel (ULSD), $20 \%$ biodiesel (B20), and $99 \%$ biodiesel (B99) on consecutive days. The vehicle, with a similar aftertreatment system, was then tested at the California Air Resources Board (CARB) Los Angeles Heavy-Duty Emissions Lab and tested on the Urban Dynamometer Driving Schedule (UDDS) to again assess the effects of ULSD, B20, and B99 on the performance of the urea-SCR aftertreatment system.
\end{abstract}

Results from this testing showed that oxides of nitrogen $\left(\mathrm{NO}_{\mathrm{x}}\right)$ emissions increased by $6 \%-12 \%$ when the blend was increased from ULSD to B20, by $16 \%-35 \%$ when the blend was increased from ULSD to B99, and by $26 \%-27 \%$ when it was increased from B20 to B99. Particulate matter (PM) emissions decreased by $37 \%$ $50 \%$ when the blend was increased from ULSD to B20, by $71 \%-79 \%$ when it was increased from ULSD to B99, and by $60 \%-63 \%$ when it was increased from B20 to B99. The SCR system reduced $\mathrm{NO}_{\mathrm{x}}$ emissions by $64 \%$ $87 \%$, and its performance was not affected by the use of biodiesel.

\section{INTRODUCTION}

Biodiesel is a renewable fuel produced from vegetable oil, animal fat, or waste cooking oil. It consists of monoalkyl esters of fatty acids, typically methyl esters, that are required to meet the requirements of ASTM standard D6751 in the United States. Biodiesel is normally used at up to a 20 volume percent blend (known as B20) with petroleum diesel, although there is some use of higher 
percentage blends. A number of controlled fleet evaluations have been performed for B20 [1-3], and these typically showed only minor effects on operability as long as the biodiesel used to make the blend met the ASTM standard requirements.

In order to meet the U.S. Environmental Protection Agency's (EPA's) 2010 standard for heavy-duty engines of $0.2 \mathrm{~g} / \mathrm{bhp}-\mathrm{h}$ for $\mathrm{NO}_{\mathrm{x}}$, many manufacturers are turning to selective catalytic reduction (SCR) with ammonia (supplied as urea) as the reductant. Only limited results of biodiesel blend performance with $\mathrm{NO}_{x}$ SCR catalysts have been reported. Williams and coworkers compared ULSD and B20 and observed no difference in the performance of an Fe-zeolite SCR catalyst tested on a medium-duty engine [4]. Subsequent testing showed lower levels of hydrocarbon adsorption and consequent inhibition of the SCR reaction at low exhaust temperatures for B20 vs. ULSD [5]. Tatur and coworkers [6] tested a light-duty vehicle equipped with a diesel particle filter (DPF)/SCR system (Fe-zeolite SCR catalyst). The emission control system was aged to 120,000 miles on B20. The SCR system's performance was initially fuel-neutral; however, significant performance degradation was observed over the 120,000 -mile aging. The degradation may have been thermal deactivation from combustion of adsorbed hydrocarbon leading to very high catalyst temperatures a situation that would likely have been worse for ULSD because of higher exhaust hydrocarbon concentration. Alternatively, alkali metals present in the biodiesel may have poisoned the SCR catalyst.

To provide additional insight into the performance of biodiesel with a range of SCR catalysts, here we report results for on-highway and chassis dynamometer testing of heavy-duty trucks retrofitted with a vanadia-based SCR catalyst.

The City of Santa Monica was contracted by the South Coast Air Quality Management District (SCAQMD) to demonstrate the viability of biodiesel used in tandem with SCR. This project is intended to demonstrate the feasibility of a retrofit SCR system to approach 2010 federal $\mathrm{NO}_{x}$ emissions standards while identifying strategies for addressing the issues associated with greater use of biodiesel.

The results from this testing, documented in this paper, show (1) the effects of varied blends of biodiesel on a urea-SCR aftertreatment system under both on-road and in-lab environments, (2) the effects of varied blends of biodiesel on the standard engine system (no SCR) under both on-road and in-lab environments, and (3) the interactive effects on emissions of biodiesel and a ureaSCR system under both on-road and in-lab environments.

The $\mathrm{NO}_{\mathrm{x}}$ and $\mathrm{PM}$ emissions are compared under all the conditions described in this paper.

\section{ON-ROAD TRUCK \& TESTING METHODS}

\section{TEST PLAN}

The project was conducted in three phases:

1. Field testing of a vehicle fueled with B20, B99, and ULSD and without an SCR system. The truck was tested both loaded and unloaded (load $=20-25$ tons).

2. Field testing of a vehicle fueled with B20, B99, and ULSD and with an SCR system. The truck was tested both loaded and unloaded (load $=20-25$ tons).

3. Laboratory testing of the vehicle at the California Air Resources Board (CARB) facility in Los Angeles for B20, B99, and ULSD fuel both with and without the SCR system installed. The testing was conducted under "loaded" conditions $(60,678 \mathrm{lb}$ test weight).

\section{HARDWARE TESTED}

Truck: The truck tested (Santa Monica \#15921) was a 2005 International 9200i tractor equipped with a 2004 Caterpillar $400 \mathrm{hp} \mathrm{C13} \mathrm{engine} \mathrm{with} \mathrm{approximately} \mathrm{71,000}$ miles on it at the beginning of this testing. The gross vehicle weight of the truck as tested was between 72,000 and $80,000 \mathrm{lb}$. The empty (unloaded) weight of the truck and trailer was approximately $36,000 \mathrm{lb}$. This truck is representative of the transfer truck fleet that the city is currently using (see Figure 1). The engine was certified to the $2.5 \mathrm{~g} / \mathrm{bhp}-\mathrm{h}$ EPA standard and was equipped with a diesel oxidation catalyst.

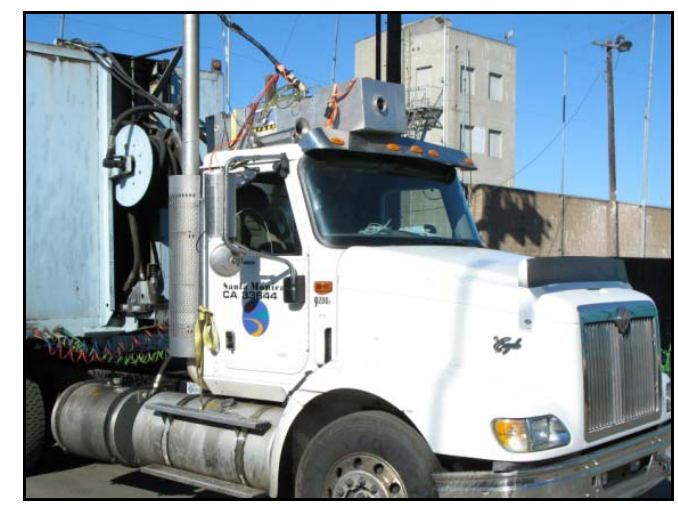

Figure 1. Santa Monica Truck \#15921 with Portable Emission Measurement Equipment Installed

SCR System: The urea-SCR system tested (not CARBverified) consists of a Grundfos Gen2.5 urea dosing system for mixing and injecting the urea and a HaldorTopsoe titania-vanadia-tungsten SCR catalyst. The dosing system came complete with injection and mixing hardware and employs feedback control based on the catalyst inlet $\mathrm{NO}_{x}$ concentration measured using a Siemens-NGK sensor in front of the catalyst, mass air flow, and exhaust temperatures at the inlet and outlet of 
the catalyst. Urea was metered in proportion to the mass emissions of $\mathrm{NO}_{x}$ when both the inlet and outlet temperatures exceed $200^{\circ} \mathrm{C}$. The metering pump was a positive displacement unit that displaced a fixed volume of urea per revolution. The volume of the SCR catalyst was $23 \mathrm{~L}$. The dosing system was air-assisted, meaning that liquid urea is injected into flowing compressed air that carries the urea to the injection nozzle and helps to atomize droplets and vaporize them. The air injection continues for 30 seconds after urea injection is stopped to purge the delivery tube and nozzle of urea. Compressed air was supplied to the dosing pump from the vehicle's compressed air supply.

The $\mathrm{NO}_{x}$ sensor and urea injection nozzle were installed approximately $3 \mathrm{ft}$ and $3.5 \mathrm{ft}$ from the catalyst inlet, respectively. The original equipment muffler was removed and replaced with the SCR catalyst. Temperature sensors were mounted immediately before and after the catalyst substrate.

Figure 2 shows the system as installed behind the truck, and Figure 3 shows a system schematic.

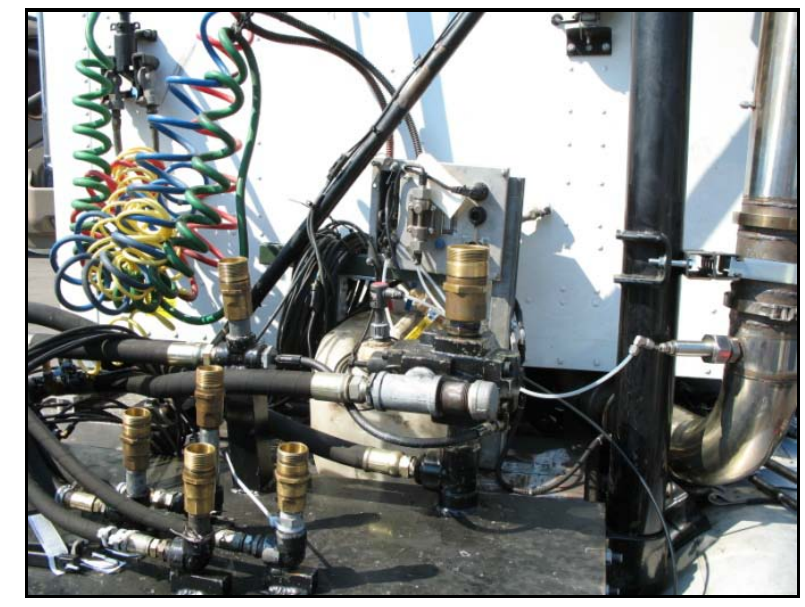

Figure 2. Extengine System Shown as Installed

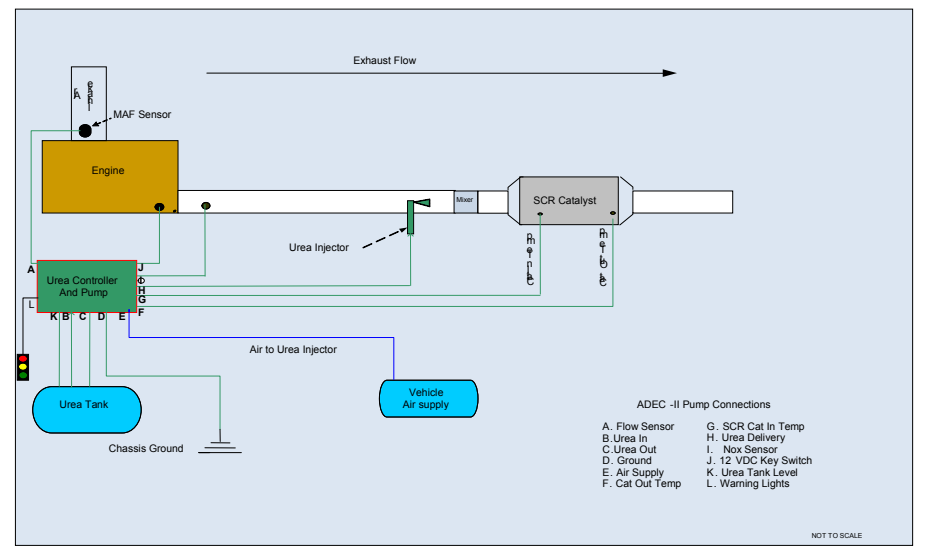

Figure 3. Extengine ADEC SCR System Schematic

\section{PORTABLE EMISSIONS MEASUREMENT EQUIPMENT AND TESTING METHOD}

The equipment used to measure the on-road performance of the biodiesel and SCR system on the truck was a Ride Along Vehicle Emissions Measurement System (RAVEM ${ }^{\mathrm{TM}}$ ) portable emissions measurement system provided by Engine, Fuel, and Emissions Engineering, Inc. This system has been benchmarked against other portable emission measurement systems such as the West Virginia University mobile laboratory and the University of California-Riverside CERT mobile laboratory, and the results showed fairly good correlation $[7,8]$ for $\mathrm{NO}_{\mathrm{x}}$ and PM. The variation observed is within the typical range of disagreement found among different heavy-duty full-flow CVS chassis dynamometer systems tested in round robin testing [9]. It is a fully integrated and portable system with the following included for the on-road portion of the testing:

- Measures $\mathrm{NO}_{\mathrm{x}}$, carbon dioxide $\left(\mathrm{CO}_{2}\right)$, carbon monoxide (CO), PM and ammonia slip

- Uses mini-constant volume sampling (CVS), dilutes only a fraction of total exhaust

- Measures $\mathrm{NO}_{x}$ using California Analytical Instruments HCLD 400 (chemiluminescence) and sampled from integrating bags

- Measures $\mathrm{CO}$ and $\mathrm{CO}_{2}$ by nondispersive infrared (NDIR) analysis and samples from integrating bags

- Measures PM by filters from diluted exhaust, partial flow

- Measures ammonia $\left(\mathrm{NH}_{3}\right)$ and nitrous oxide $\left(\mathrm{N}_{2} \mathrm{O}\right)$ by Fourier transform infrared (FTIR) analysis

The equipment was mounted on top of the cab of the truck for the duration of the testing. Figure 4 shows some details of this installation.

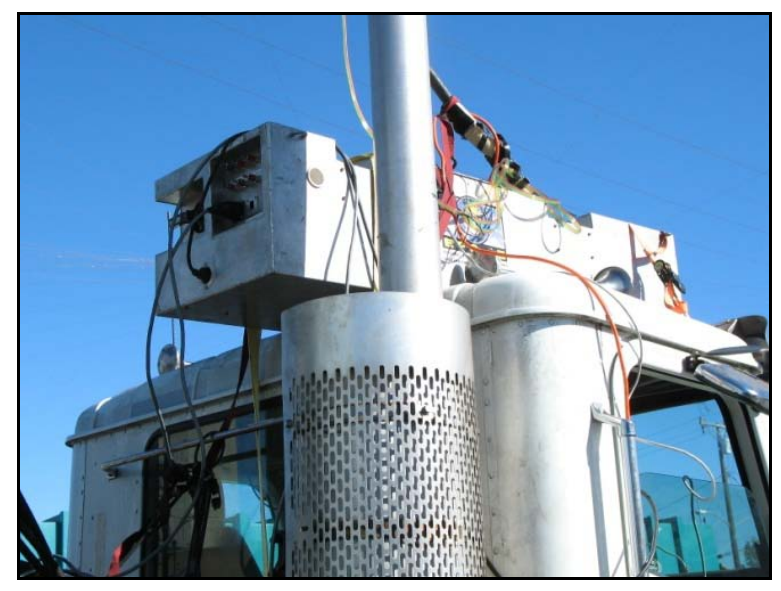

Figure 4. Installed RAVEM System on Test Vehicle 


\section{LABORATORY EMISSIONS MEASUREMENT EQUIPMENT AND TESTING METHOD}

The test was conducted over the urban dynamometer driving schedule (UDDS) (shown in Figure 5) at a dynamometer facility operated by the CARB Heavy-Duty Diesel Emission Testing Laboratory located at the Los Angeles County Metropolitan Transit Authority Regional Rebuild Center near downtown Los Angeles. The test vehicle was placed on a chassis dynamometer (Schenck-Pegasus) with a range of simulated inertial weights from 5,000 to $100,000 \mathrm{lb}$ and capable of absorbing up to $660 \mathrm{hp}$. A warm-up UDDS cycle was completed before every recorded UDDS test run. Vehicle exhaust was diluted in a Horiba critical flow venturi-constant volume sampler (CFV-CVS) with an 18in. diameter primary dilution tunnel that was operated at $2,500 \mathrm{scfm}$. Standard gaseous pollutants and particulate emission samples were collected as specified in the Code of Federal Regulations (40 CFR, Part 86, Subpart $\mathrm{N})$. Primary dilution air for the tunnel was passed through high-efficiency particulate air (HEPA) filters and a bed of charcoal before entering the tunnel. The total PM samples for mass emission measurements were collected under double-dilution conditions from a 5-in.diameter secondary dilution tunnel with prefiltered dilution air (air passed through a HEPA filter capsulecartridge).

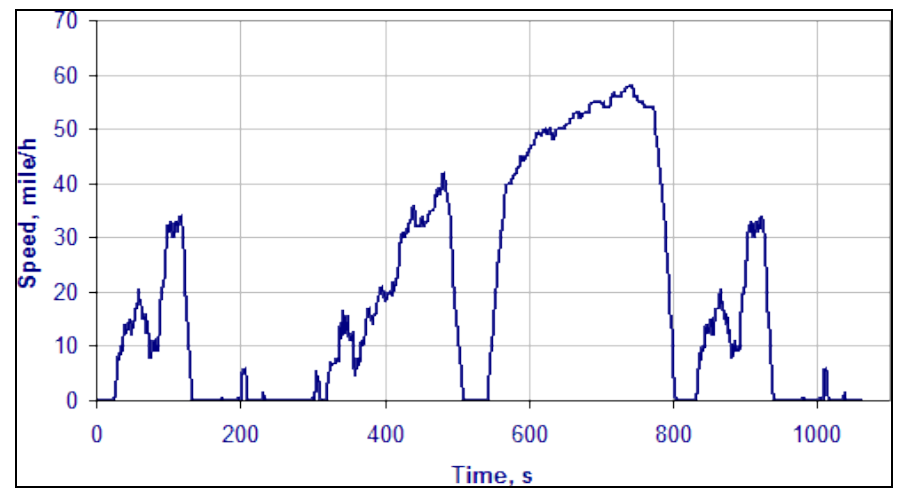

Figure 5. Heavy-Duty UDDS Cycle (courtesy of dieselnet.com)

Criteria air pollutants $\left(\mathrm{NO}_{\mathrm{x}}, \mathrm{CO}\right.$, and total hydrocarbons, or $\mathrm{THC}$ ) and a greenhouse gas $\left(\mathrm{CO}_{2}\right)$ were each analyzed on site using a Horiba gas bench with chemiluminescent, NDIR, and flame ionization detection analyzers, respectively. The PM samples for gravimetric analysis were collected on $47-\mathrm{mm}$ Teflo $^{\mathrm{TM}}(2.0 \mathrm{~mm}$ pore size) Teflon membrane filters (Pall-Gelman, Ann Arbor, Michigan). Temperature and humidity-controlled chambers were used for conditioning and weighing the clean and sampled filter substrates. Filter weights were determined using a microbalance with a $\pm 0.1 \mu \mathrm{gg}$ sensitivity (Model UMX2, Mettler Toledo International Inc., USA). Preweighed filter substrates were stored in closed glass petri dishes in the conditioning chamber before and after sampling.

\section{SANTA MONICA DUTY CYCLE INFORMATION}

The City of Santa Monica operates transfer trucks to haul refuse from the City of Santa Monica transfer station to the waste-to-energy plant located in Commerce, California. The distance between the transfer station and the plant is approximately 20.9 miles $(33.5 \mathrm{~km})$. Route data were taken during on-road emissions testing both loaded to Commerce and unloaded back to the Santa Monica yard to ensure typical operation of the trucks and to quantify the speedtime trace for the emissions and fuel economy measurements. A representative graph of speed vs. time is shown in Figure 6. Runs were between 27 and 58 minutes long and varied traffic conditions.

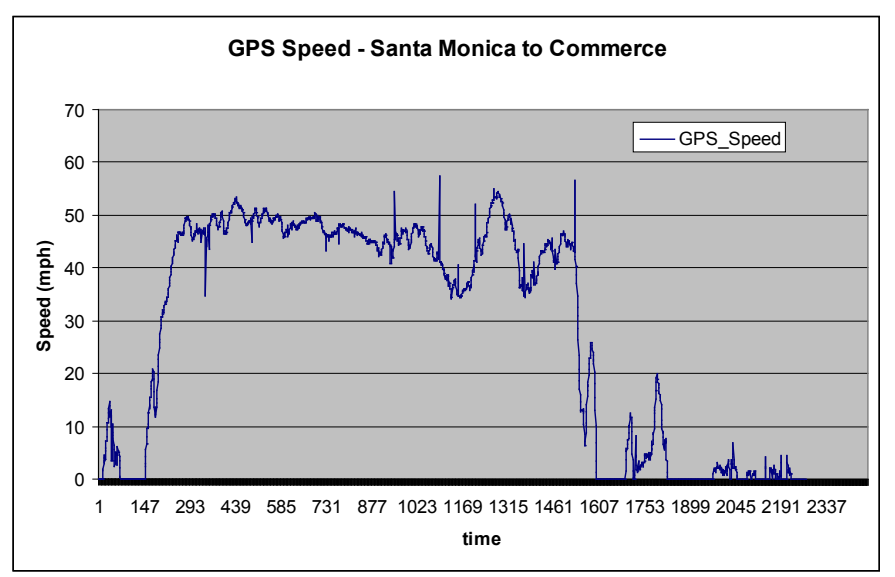

Figure 6. Speed Trace of Typical Run to Commerce

Multiple runs on various days were repeated on the same route (Santa Monica to Commerce and back) for each fuel and exhaust aftertreatment. Traffic patterns had typical day-to-day variations but were as consistent as possible given the real-world nature of the testing. Runs that took longer than 58 minutes were excluded from this report because they were determined to be nontypical as a result of the heavy volume of traffic.

\section{FUEL USED}

The ULSD and B99 were delivered to test tanks at the Santa Monica facility. The B20 was blended on site from the test tanks of B99 and ULSD. A complete analysis was done on the both the ULSD and B99. Blend percent and stability tests were run on the biodiesel fuels to ensure the fuel quality of all sets of tests. Results, presented in Appendix A, showed that the B99 failed current ASTM specs on carbon residue, calcium plus magnesium, and flashpoint. These results were not available until after the on-road testing was completed, and while they show that this biodiesel is not of adequate quality for commerce, we believe this has little effect on emissions performance over the relatively short time of biodiesel use covered in this study. 
Carbon residue is an approximate measure of the tendency of a fuel to form carbon deposits in the engine, generally a long-term durability issue. High carbon residue might be caused by contamination with lube oil or high levels of bound glycerin. Unfortunately, free and total glycerin (which includes bound glycerin) cannot be accurately measured for diesel-biodiesel blends such as B99. Metals such as calcium and magnesium can contribute to injector, fuel pump, piston, and ring wear as well as to injector deposits. It is also possible that these metals can negatively affect the performance of emission control catalysts. In both cases this is a longer-term durability concern. The primary purpose of the flashpoint specification is to limit levels of residual methanol present in biodiesel to less than $0.2 \mathrm{wt} \%$. High levels of methanol can be incompatible with elastomeric components on the engine, also a long-term durability concern.

\section{RESULTS}

\section{ON-ROAD EMISSIONS TEST RESULTS - BASELINE TRUCK, NO SCR}

The $\mathrm{NO}_{\mathrm{x}}$ and $\mathrm{PM}$ emissions results are supplied from the portable system and are described below [10]. Analysis was completed and results are discussed for two duty cycles to Commerce and from Commerce, as these data sets represented the two distinct duty cycles encountered by the truck - full and empty load. The difference in weight is approximately 20 tons. The route was the same in both directions, though speeds were variable because of traffic. The statistical significance of the results and the variation in results is discussed below.

Baseline Vehicle (no SCR) - to Commerce (loaded condition): $\mathrm{NO}_{x}$ and PM Emission Changes due to ULSD, B20, and B99.

The loaded truck (to Commerce) provided only three test runs for B99 (37.1 minutes avg.), compared with five runs for ULSD (35.0 minutes avg.) and five runs for B20 (37.6 minutes avg.); results are shown in Figures 7 and 8 at the $95 \%$ confidence interval. Differences in confidence intervals are probably caused by variations in driving conditions, travel time, payload, and sample sizes. The $\mathrm{NO}_{\mathrm{x}}$ emission differences for ULSD and B99 and for B20 and B99 are not significant with any degree of confidence ( $p=0.11$ for ULSD vs. B99 and $p=0.46$ for B20 vs. B99). Emission differences of approximately $12 \%$ are likely between ULSD and B20 $(p=0.05)$.

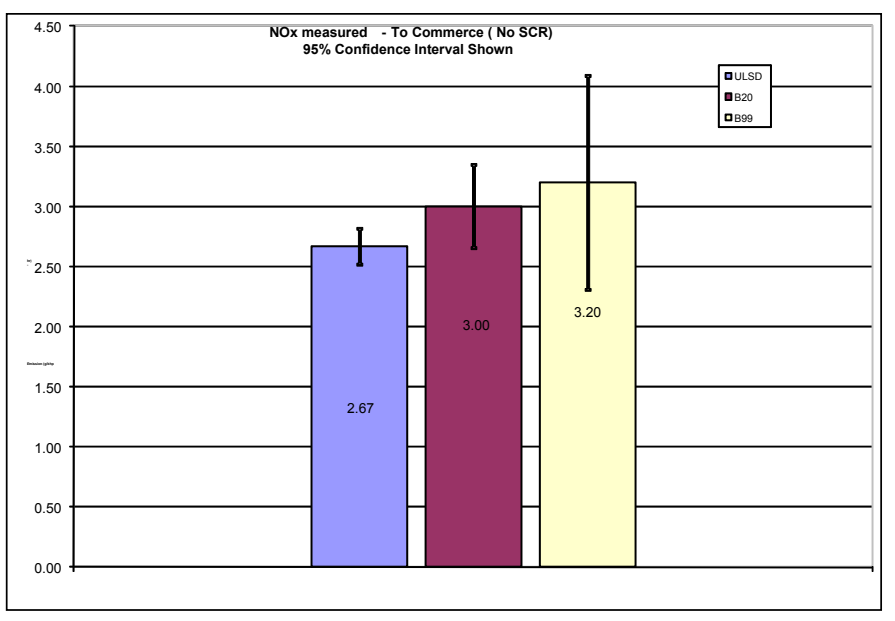

Figure 7. $\mathrm{NO}_{\mathrm{x}}$ Emissions for Three Fuels in Loaded, Baseline Condition (no SCR)

Differences in PM emissions for ULSD vs. B20 and B99 are statistically significant at the $95 \%$ level. The PM decreased by $50 \%$ for B20 in comparison to that of ULSD ( $p=0.00$ ); PM decreased by $72 \%$ for B99 when compared with that of ULSD $(p=0.01)$. See Figure 8 .

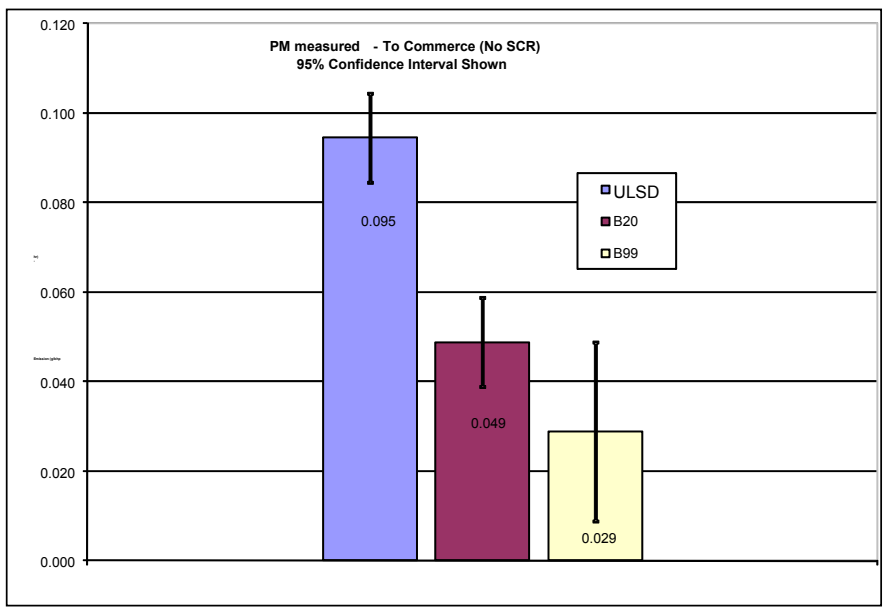

Figure 8. PM Emissions for Three Fuels in Loaded, Baseline Condition (no SCR)

Baseline Vehicle (no SCR) - from Commerce (unloaded condition): $\mathrm{NO}_{x}$ and PM Emission Changes due to ULSD, B20, and B99.

This test was similar to that described in the previous section, except that the truck had a lighter load. The unloaded truck (from Commerce) provided six test runs with B99, four with ULSD, and four with B20; results are shown in Figures 9 and 10 . The $\mathrm{NO}_{\mathrm{x}}$ emission differences between ULSD and B20 and between B20 and B99 are not significant with any degree of confidence $(p=0.20$ for ULSD vs. B20 and $p=0.78$ for B20 vs. B99). Emissions differences of approximately $27 \%$ are likely between ULSD and B99 $(p=0.004)$. 


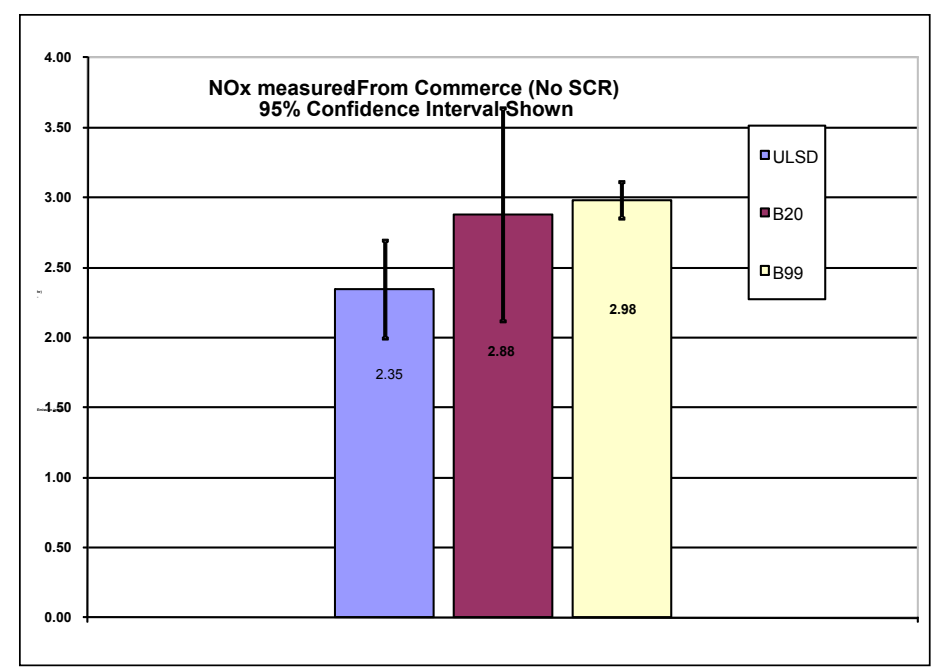

Figure 9. $\mathrm{NO}_{\mathrm{x}}$ Emissions for Three Fuels in Unloaded, Baseline Condition (no SCR)

Differences in PM emissions for ULSD vs. B20 and B99 are statistically significant at the $95 \%$ level. The PM decreased by $37 \%$ for B20 in comparison to ULSD ( $p=$ 0.002); PM decreased by $71 \%$ for $B 99$ in comparison to $\operatorname{ULSD}(p=0.000)$. See Figure 10.

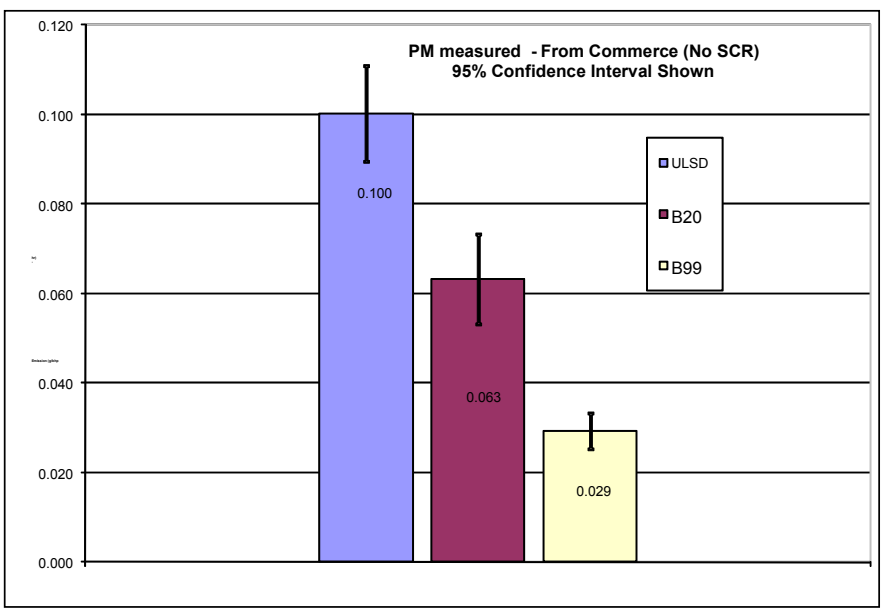

Figure 10. PM Emissions for Three Fuels in Unloaded, Baseline Condition (no SCR)

\section{ON-ROAD EMISSIONS TEST RESULTS - WITH SCR INSTALLED ON TRUCK}

The testing of the SCR system took place approximately 60 days after completion of the baseline (non-SCR truck). The purpose of this round of testing was to see the effects of biodiesel blends on an SCR system when used on the truck. Runs with test times in excess of 58 minutes were omitted because they resulted from heavy traffic. Seven test runs were omitted from this data set. The extremely long run times were an indication that the duty cycle was significantly different and not appropriate for comparison to other runs.
Fuel used for this round of tests consisted of the same ULSD and B99 and hand mixing of the same ULSD and B99 to obtain a B20 blend. Appendix A shows the fuel properties as tested for the ULSD and B99. Acid values were measured to determine if the fuels had degraded from oxidation during the 60-day interim period. These and the blend percent are listed in Table 1, and the results indicate no significant degradation.

Table 1. SCR Testing Fuel Properties

\begin{tabular}{|c|l|l|l|}
\hline Fuel Sample Date & Result & Acid Value & Acid Value \\
\hline & Blend \% & (as rec'd) & (extrapolated to B100) \\
\hline $01 / 31 / 07$ & 18.7 & $<0.1$ & $<0.5$ \\
\hline $02 / 01 / 07$ & 18.1 & $<0.1$ & $<0.5$ \\
\hline $02 / 12 / 07$ & 19.4 & $<0.1$ & $<0.5$ \\
\hline $03 / 07 / 07$ & 100 & $<0.1$ & $<0.1$ \\
\hline $03 / 29 / 07$ & 18.2 & $<0.1$ & $<0.5$ \\
\hline $04 / 06 / 07$ & 100 & 0.42 & 0.42 \\
\hline
\end{tabular}

Statistical significance is discussed for each comparison for the following tests:

Vehicle w/SCR Installed - to Commerce (loaded condition): $\mathrm{NO}_{x}$ and PM Emission Changes due to ULSD, B20, and B99

The loaded truck (to Commerce) with the SCR system installed and functional resulted in emissions analysis from three runs with B20 (37.3 minutes avg.), six runs for ULSD (33.0 minutes avg.) and four runs with B99 (31.6 minutes avg.). Results are shown in Figures 11 and 12.

Differences in $\mathrm{NO}_{\mathrm{x}}$ emissions between ULSD and B20 and between B20 and B99 are not significant with a high degree of confidence ( $p=0.10$ for ULSD vs. B20, and $p$ $=0.18$ for B20 vs. B99). Emissions differences of approximately $16 \%$ are likely between ULSD and B99 ( $p$ $=0.05)$. See Figure 11.

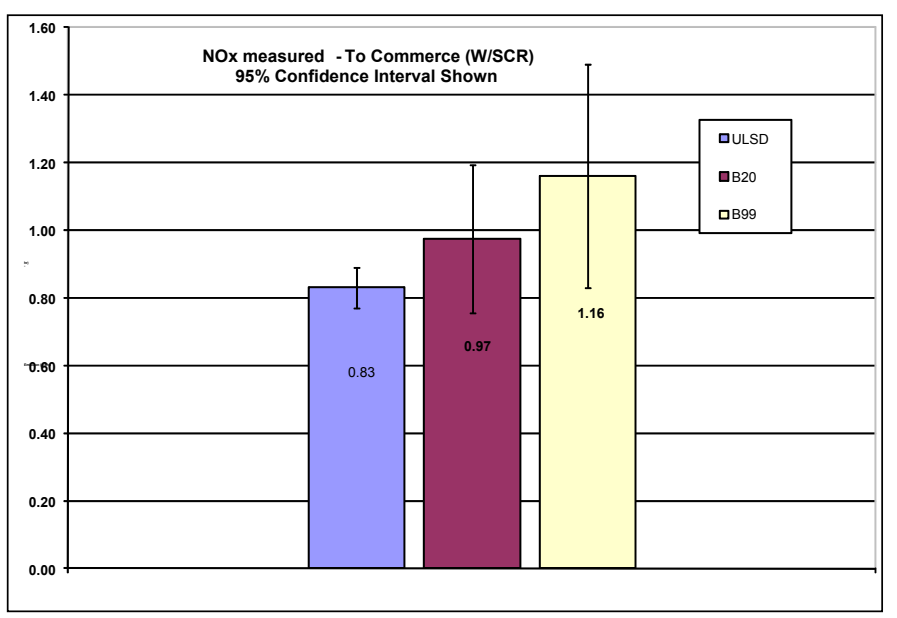

Figure 11. $\mathrm{NO}_{\mathrm{x}}$ Emissions for Three Fuels In Loaded, SCR-Equipped Truck

Differences in PM emissions for ULSD vs. B99 and B20 vs. B99 are statistically significant at the $95 \%$ level and are shown in Figure 12. The PM decreased by $63 \%$ for 
B99 in comparison to B20 $(p=0.02)$. The PM decreased by $71 \%$ for B99 in comparison to ULSD $(p=0.00)$. Differences in PM for ULSD vs. B20 were not statistically significant $(p=0.10)$.

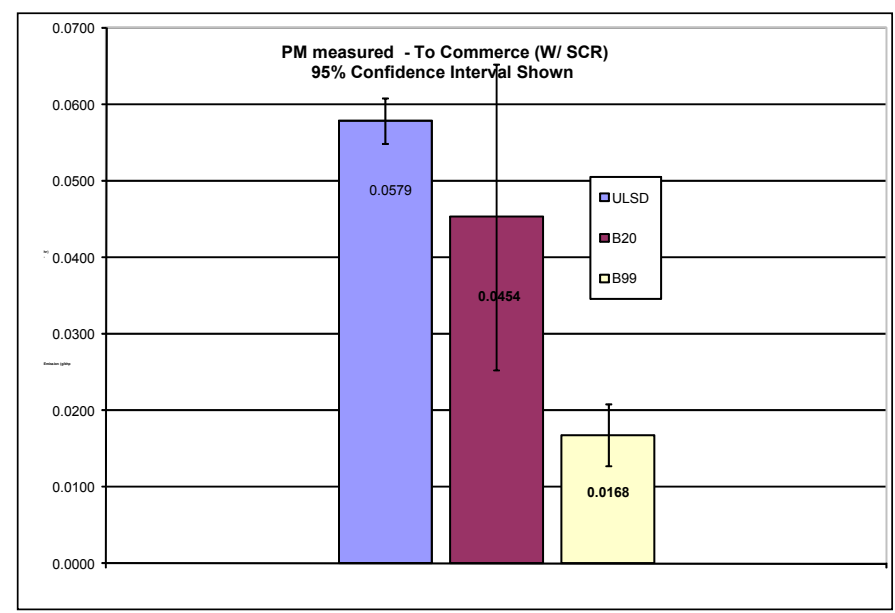

Figure 12. PM Emissions for Three Fuels In Loaded, SCR-Equipped Truck

Vehicle w/SCR installed - from Commerce (unloaded condition): $\mathrm{NO}_{x}$ and PM Emission Changes due to ULSD, B20, and B99

The unloaded truck (from Commerce) with the SCR system installed and functional resulted in emissions analysis from only two runs with B20 (40 minutes avg.), five runs for ULSD (35.3 minutes avg.) and three runs with B99 (32.2 minutes avg.). Again, because of the high variability in the data collected and the limited amount of runs for B20, there appears to be no statistical significance between the means of the ULSD, B99, and B20 $\mathrm{NO}_{\mathrm{x}}$ emissions for the loaded truck, as shown in Figure $13(p=0.15-0.72)$.

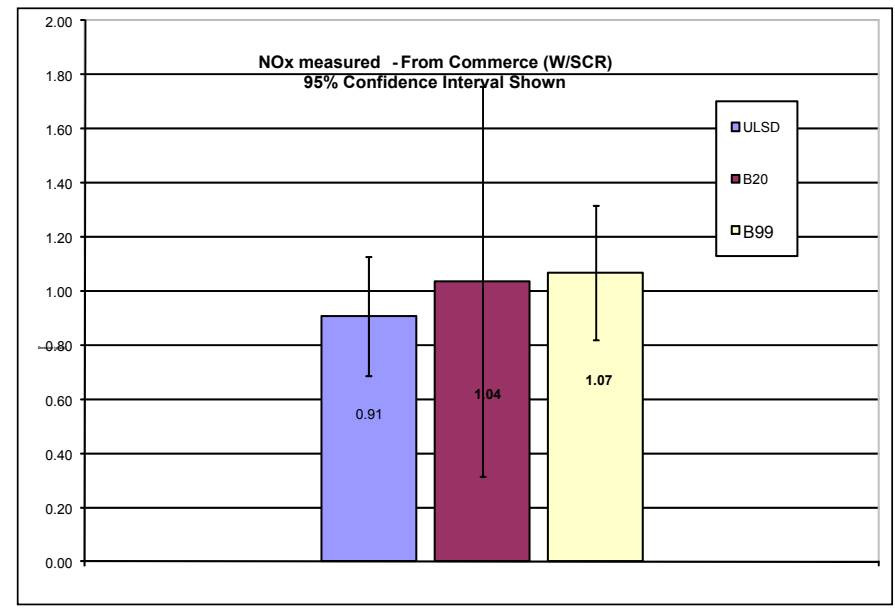

Figure 13. $\mathrm{NO}_{x}$ Emissions for Three Fuels in Unloaded, SCR-Equipped Truck

The difference in PM emissions for the ULSD vs. B99 is statistically significant at the $95 \%$ level. The PM decreased by $74 \%$ for $\mathrm{B} 99$ in comparison to ULSD; PM differences for ULSD vs. B20 and B20 vs. B99 are not statistically significant because of the variation and small sample size $(2)$ measured for B20 $(0.12<p<0.22)$. See Figure 14 for PM emissions.

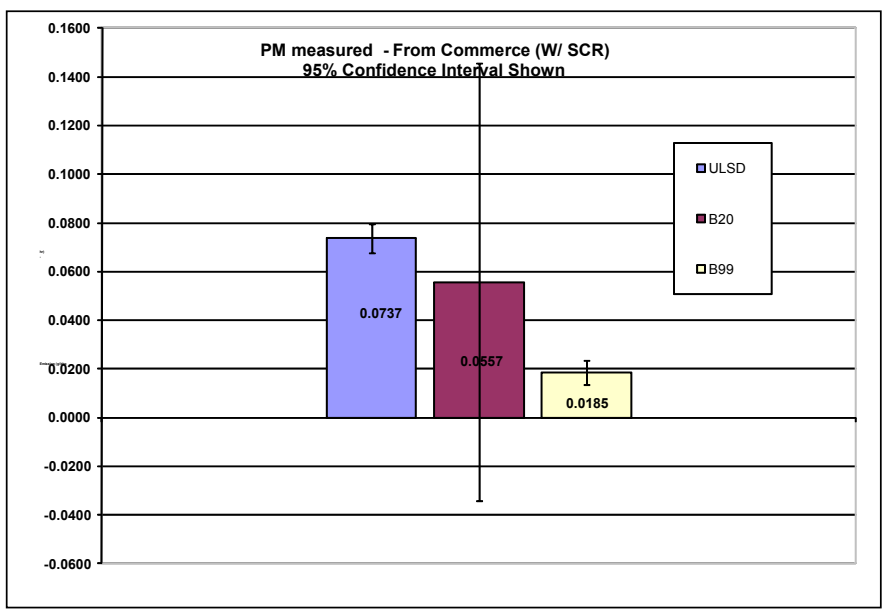

Figure 14. PM Emissions for Three Fuels in Unloaded, SCR-Equipped Truck

\section{IN-LABORATORY EMISSIONS TEST RESULTS: WITH AND WITHOUT SCR INSTALLED}

\section{VEHICLE TESTED}

For a second set of data and verification of the results observed during the on-road testing, the same Santa Monica truck (vehicle \# 15921) was tested at the CARB LA Metro Laboratory in Los Angeles, California, in February 2009 (almost 24 months after on-road data were collected on this vehicle).

The truck was again tested with and without the retrofitted urea SCR system and simulated a 60,678 lb test weight. Before the tests, this vehicle was found to burn a significant amount of lubricating oil. Caterpillar's oil consumption measurement procedure (Caterpillar's Bulletin, 2007 [11]) recommends the investigation of any engine of this age using less than 60 gallons of fuel per quart of oil. The test vehicle's fuel to lubricating oil consumption ratio was measured over the course of 1,000 miles to be 53.5 gallons of fuel per quart of oil, which is $12 \%$ less than the minimum allowable. Therefore, the test vehicle is categorized as a high-oilconsumption vehicle. The presence of excess lubricating oil in the combustion and exhaust stream may cause observed emission rates from this vehicle to differ from those of vehicles whose engines are still within the manufacturer's specifications, and emissions can also be different from those observed when the vehicle was initially tested. This could also add to the variability seen in PM measurement during this phase of the test.

The SCR system was modified to include a different dosing pump, which may have resulted in a higher 
efficiency for $\mathrm{NO}_{x}$ reduction than the on-road testing. It was found during the on-road testing that the engine had extremely low ammonia slip, and it was determined that additional dosing could be tolerated for this system setup. The SCR catalyst used during in-lab testing was the same one used during on-road testing; $95 \%$ confidence intervals are shown in each figure.

Vehicle w/SCR Installed - UDDS cycle: $\mathrm{NO}_{x}$ and PM Emission Changes due to ULSD, B20, and B99

The truck was tested at the CARB facility with the SCR system installed and functional, and this resulted in emissions analysis from three runs with B20, three runs with ULSD, and three runs with B99. There is a statistically significant difference in means between ULSD vs. $\mathrm{B} 99$ as well $\mathrm{B} 20$ vs. B99. The $\mathrm{NO}_{\mathrm{x}}$ emissions increased by $35 \%$ for ULSD vs. B99 $(p<0.01)$. The $\mathrm{NO}_{x}$ emissions increased by $26 \%$ for B20 vs. B99 $(p<0.01)$. Differences in $\mathrm{NO}_{x}$ emissions of approximately $7 \%$ are likely (with higher variability due to limited test runs and vehicle performance), as shown in Figure 15 for ULSD vs. B20 $(p=0.07)$.

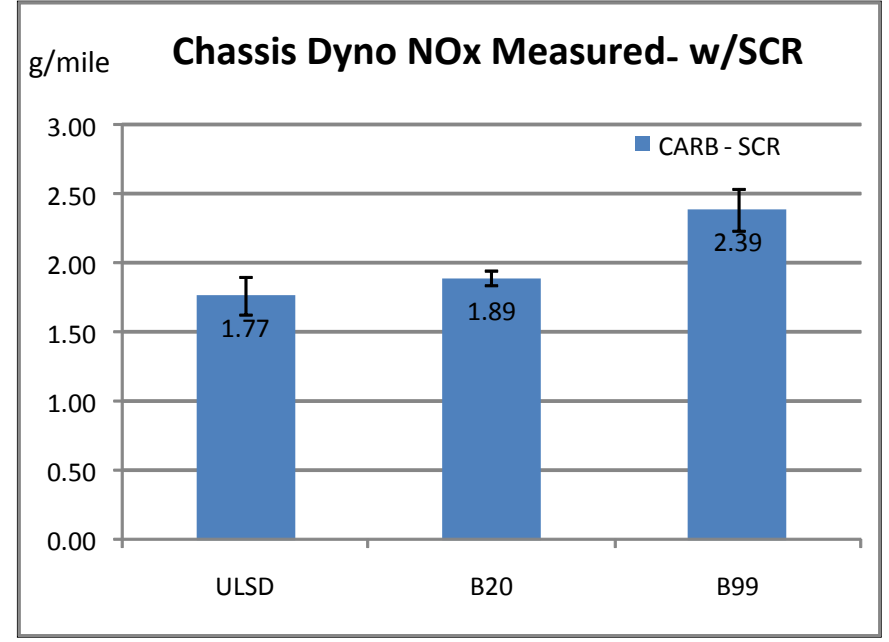

Figure 15. $\mathrm{NO}_{\mathrm{x}}$ Emissions at CARB Lab (SCR installed)

Based on the high variability observed in the data (possibly due to the high level of oil that the vehicle was burning) and the limited amount of runs, there appears to be no statistical significance between the means of the ULSD, B20, and B99 for PM emissions $(0.10<P<$ 0.42 ) for the truck, as shown in Figure 16 (again, using the Student t-test at a 95\% confidence level).

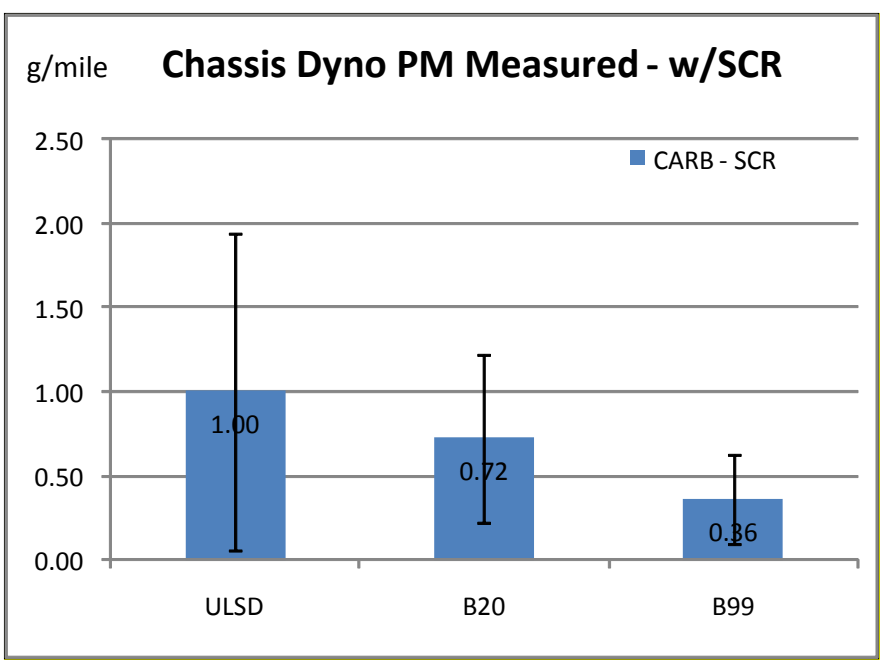

Figure 16. PM Emissions at CARB Lab (SCR installed)

Vehicle with No SCR installed - UDDS Cycle: $\mathrm{NO}_{x}$ and PM Emission Changes due to ULSD, B20, and B99

The truck was tested at the CARB facility with the SCR system removed; the result was an emissions analysis from three runs with B20, three runs with ULSD, and three runs with B99. There is a statistically significant difference in means between ULSD vs. B99 as well as B20 vs. B99. The $\mathrm{NO}_{x}$ emissions increased by $34 \%$ for ULSD vs. B99 $(p=0.01)$. The $\mathrm{NO}_{x}$ emissions increased by $27 \%$ for $B 20$ vs. B99 ( $p=0.01$ ); $\mathrm{NO}_{x}$ emission differences of approximately $6 \%$ are likely (with higher variability due to limited test runs and vehicle performance), as shown in Figure 17 for ULSD vs. B20 $(p=0.06)$.

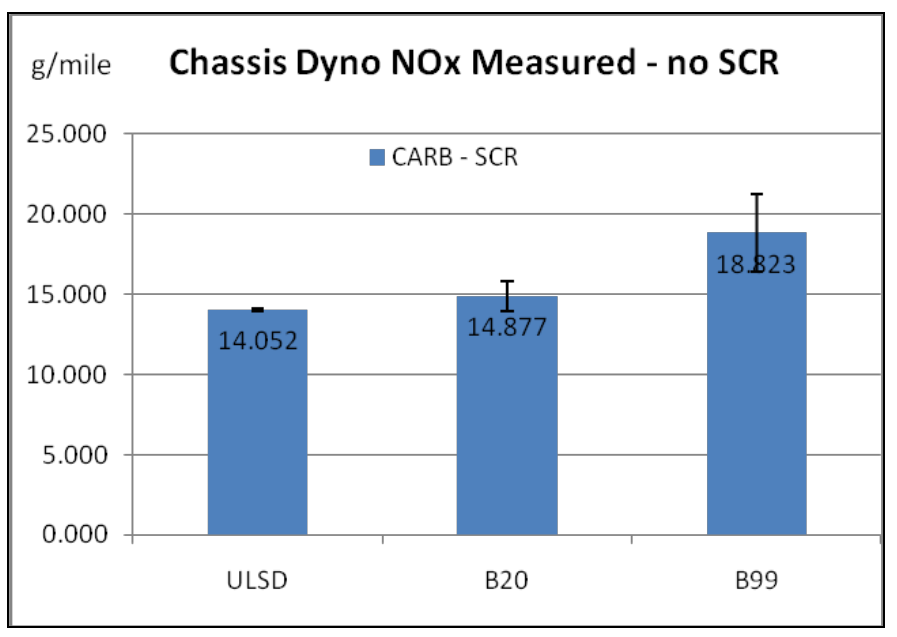

Figure 17. $\mathrm{NO}_{\mathrm{x}}$ Emissions at CARB (baseline, no SCR) 
There is statistical significance between the means of the ULSD, B20, and B99 PM emissions for the truck, as shown in Figure 18 (using the Student t-test at a 95\% confidence level). The PM reduction observed for B20 vs. ULSD was $49 \%(p<0.01)$. The PM reduction observed for B99 vs. ULSD was $79 \%(p=0.01)$. The PM reduction observed for B99 vs. B20 was $60 \%(p=0.02)$.

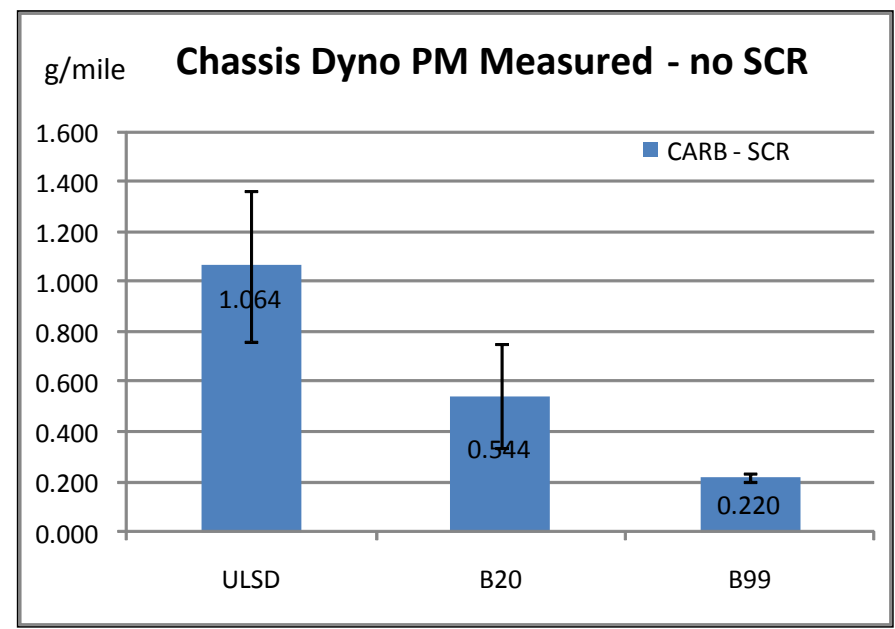

Figure 18. PM Emissions at CARB Lab (baseline, no SCR)

\section{CONCLUSIONS}

\section{SPECIFIC CONCLUSIONS}

The NO${ }_{x}$ emission differences due to variable blends of biodiesel: All test results that showed statistical significance at the 95\% confidence interval (both on-road and in-laboratory testing) showed an increase in $\mathrm{NO}_{\mathrm{x}}$ at increasing amounts of biodiesel. They are as follows:

- ULSD vs. B99: $+16 \%-24 \%$ (on-road) to $+35 \%$ (in-lab)

- B20 vs. B99: $+26 \%$ and $27 \%$ increase (both inlab)

The PM emission differences due to variable blends of biodiesel: All results that showed statistical significance at the $95 \%$ confidence level showed a reduction in PM for the addition of biodiesel vs. ULSD. The PM measurements for the truck yielded the following statistically significant results:

- ULSD vs. B99: $71 \%-78 \%$ decrease (4 results, on-road) to a $79 \%$ decrease (1 result, in-lab)

- ULSD vs. B20: $37 \%-50 \%$ decrease (2 results, on-road) to a $49 \%$ decrease (in-lab)

The $\mathrm{NO}_{x}$ reduction due to SCR: All results having statistical significance between the means show that the
$\mathrm{NO}_{x}$ reduction efficiency of the SCR system was not negatively affected by the addition of biodiesel.

On-road testing:

- The reduction in $\mathrm{NO}_{x}$ due to $\mathrm{SCR}$ during the fully loaded truck testing was $69 \%$ for ULSD, $68 \%$ for B20, and $64 \%$ for B99. These differences in reduction were not statistically significant. See Figure 19.

- The reduction in $\mathrm{NO}_{x}$ due to SCR during the unloaded truck testing was $61 \%$ for ULSD, $64 \%$ for B20, and 64\% for B99. See Figure 20.

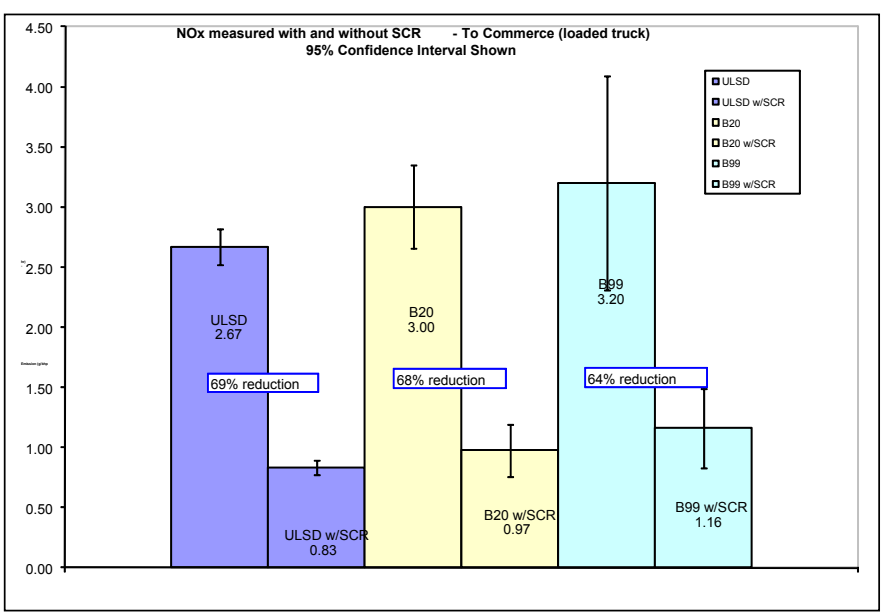

Figure 19. On-road $\mathrm{NO}_{x}$ Reductions due to Extengine SCR System (fully loaded truck)

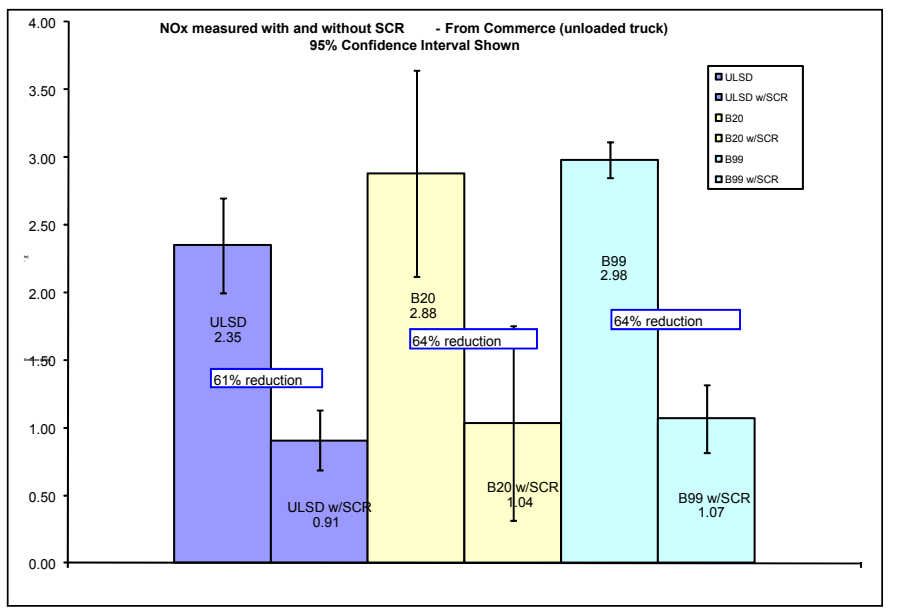

Figure 20. On-road $\mathrm{NO}_{x}$ Reductions due to Extengine SCR System (unloaded truck)

In-lab testing:

CARB in-lab test results for the $\mathrm{NO}_{x}$ reduction due to the Extengine SCR system indicate that all tests were statistically significant and showed no negative effects on SCR NO${ }_{x}$ reduction efficiency due to fuel type. The $\mathrm{NO}_{x}$ reduction was shown to be $87 \%$ for all fuels (see 
Figure 20). It should be noted again that a different dosing pump was installed in the truck for the CARB inlab testing; this may have resulted in higher SCR efficiencies than those observed in the on-road data.

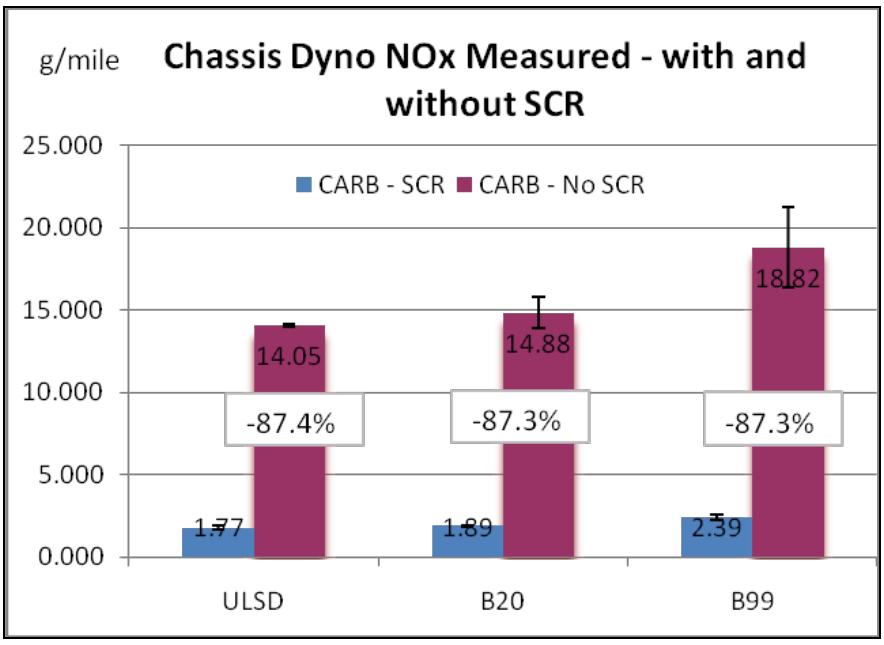

Figure 21. Laboratory $\mathrm{NO}_{\mathrm{x}}$ Reduction due to SCR System on All Fuels

\section{GENERAL CONCLUSIONS}

- Overall trends observed during the on-road and in-laboratory testing of the retrofitted Extengine SCR system as installed on the test vehicle indicated that there was not a significant decrease in the performance or efficiency of the SCR system when increased levels of biofuels were introduced.

- The use of biodiesel did result in higher $\mathrm{NO}_{x}$ emissions than the use of ULSD (in tests with statistical significance).

- The use of biodiesel did result in lower PM emissions than the use of ULSD (in tests with statistical significance).

\section{ACKNOWLEDGMENTS AND DISCLAIMER}

The author and co-authors of this report would like to acknowledge Rick Sikes and the City of Santa Monica for the use of its truck and its support for this study. The authors of this study would also like to acknowledge Tellurian Biodiesel for supplying the fuel used in this study as well as for project support. Funding for the study was provided by the South Coast Air Quality Management District as well as by the U.S. Department of Energy's Vehicle Technologies Program in the Office of Energy Efficiency and Renewable Energy.

The statements and opinions expressed in this paper are solely those of the authors and do not represent the official position of the California Air Resources Board or other participants in this project. The mention of trade names, products, and organizations does not constitute endorsement or recommendation for use.

\section{REFERENCES}

1. Fraer, R., Dinh, H., Proc, K., McCormick, R.L., Chandler, K., Buchholz, B. "Operating Experience and Teardown Analysis for Engines Operated on Biodiesel Blends (B20)," SAE Technical Paper 200501-3641 (2005).

2. Proc, K., Barnitt, R., Hayes, R.R., McCormick, R.L., Ha, L., Fang, H.L. "100,000 Mile Evaluation of Transit Buses Operated on Biodiesel Blends (B20)," SAE Technical Paper 2006-01-3253 (2006).

3. Lammert, M., Barnitt, R., McCormick, R.L. "Field Evaluation of Biodiesel (B20) Use by Transit Buses," SAE Technical Paper 2009-01-2899 (2009).

4. Williams, A., Pedersen, D., Ireland, J., McCormick, R.L., Fang, H.L. "Effect of Biodiesel Blends on Urea Selective Catalytic Reduction Catalyst Performance with a Medium-Duty Engine," SAE Technical Paper 2008-01-2484 (2008).

5. Williams, A., Ratcliff, M., Pedersen, D., McCormick, R.L., Cavataio, G., Ura, J. "Effect of Unburned Methyl Esters on the $\mathrm{NO}_{x}$ Conversion of an $\mathrm{Fe}$ Zeolite SCR Catalyst," SAE Technical Paper 200901-2777 (2009).

6. Tatur, M., Nanjundaswamy, H., Tomazic, D., Thornton, M., McCormick, R. "Biodiesel Effects on U.S. Light-Duty Tier 2 Engine and Emission Control Systems," SAE Technical Paper 2009-01-0281 (2009).

7. Weaver, C. "Results of Correlation Testing; RAVEM vs. U.C. Riverside Full-Flow CVS," September 2005.

8. Weaver, C. "Correlation between the Mexico City Governments RAVEM System and West Virginia University's Transportable Heavy Duty Emissions Laboratory," December 2006.

9. Traver, M.L., Tennant, C.J., McDaniel, T.I., McConnell, S.S., Bailey, B.K., and Maldonado, H. "Interlaboratory Cross-Check of Heavy-Duty Vehicle Chassis Dynamometers," SAE Paper No.2002-012879, SAE International, Warrendale, PA 2002.

10. Weaver, C. "On-Road Emissions from a TractorTrailer Using ULSD, B20 and B99 Fuels With and Without a Selective Catalytic Reduction - Final Report," August 2007.

11. Caterpillar's Service Warranty Bulletin: Excessive Engine Oil Consumption, Bulletin No. 6.5, 1-4, 2002. 


\section{CONTACT}

Kevin Walkowicz, Advanced Vehicle Testing and Evaluation Team Leader, National Renewable Energy Laboratory (NREL), Golden, CO.

Web: http://www.nrel.gov/vehiclesandfuels/fleettest

Email: kevin.walkowicz@nrel.gov

\section{DEFINITIONS, ACRONYMS, ABBREVIATIONS}

$\mathrm{NO}_{\mathrm{x}}$ : oxides of nitrogen

PM: particulate matter

SCR: selective catalytic reduction

B20 $20 \%$ biodiesel, $80 \%$ diesel fuel

B99: $\quad 99 \%$ biodiesel, $1 \%$ diesel fuel

ULSD: ultra-low-sulfur diesel

DOE: U.S. Department of Energy

CARB: California Air Resources Board

EPA: Environmental Protection Agency 
APPENDIX A. TEST FUEL SPECIFICATIONS

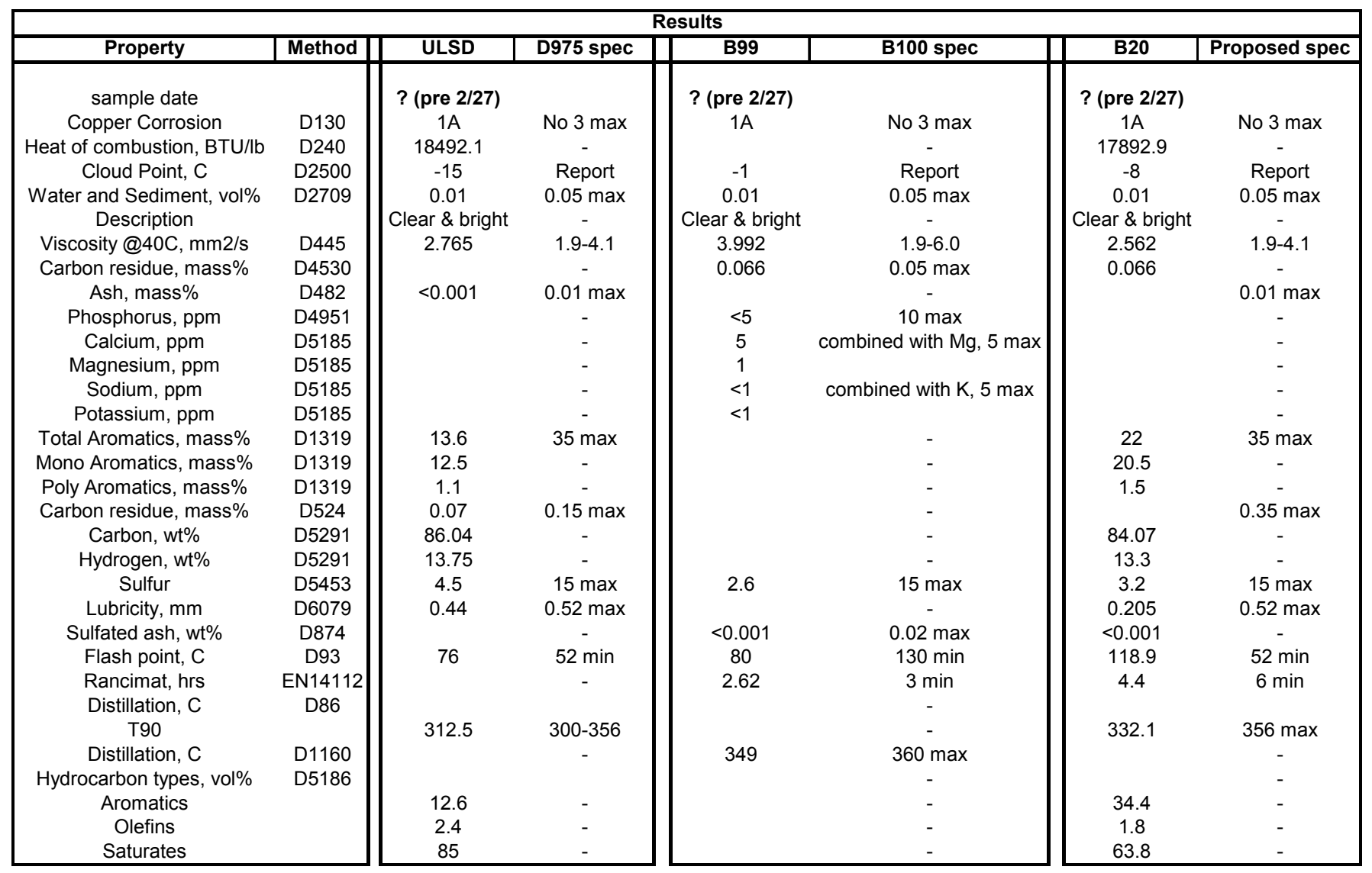

